\title{
3D CAD Systems for the Clothing Industry
}

\author{
Abu Sadat Muhammad Sayem, Richard Kennon and Nick Clarke \\ Textiles and Paper, School of Materials, The University of Manchester, P.O. Box 88, \\ Sackville Street, Manchester, M60 1QD, UK.
}

\begin{abstract}
The approaches to designing virtual garments may be categorised as " $2 \mathrm{D}$ to $3 \mathrm{D}$ " and " $3 \mathrm{D}$ to 2D”. The former refers to draping flat digital pattern pieces on a virtual mannequin, and the later indicates the development of clothing design on a realistic body and subsequent flattening into 2D pattern pieces. Several CAD systems for garment visualisation in space from flat patterns have already been introduced into the clothing industry. Any industrial application of the pattern flattening technique is yet to be made, due to the non-availability of an appropriate CAD system on the market. This paper reviews the historical developments of 3D CAD systems for the clothing industry, and assesses the features of currently-available systems on market.
\end{abstract}

Key words: 3D CAD; virtual clothing prototyping; virtual mannequin.

\section{Introduction}

Today's clothing industry increasingly prefers to use computer-aided design (CAD) technique for both fashion designing and pattern creation as it offers greater efficiency and time-saving solutions to many complicated tasks and it also facilitates Internet-based communication amongst designers, manufactures and retailers. Two dimensional (2D) graphics software packages such as Illustrator (Adobe Inc.) and CorelDRAW (Corel Corp.) or packages that have been customised for the fashion industry such as Kaledo Style (Lectra), Vision fashion studio (Gerber), Tex-Design (Koppermann) etc. are also being used around the world. Specialised 2D CAD software packages including packages such as cad.assyst (Assyst-Bullmer), Modaris (Lectra), Accumark (Gerber), Master Pattern Design (PAD 
System), TUKAcad (Tukatech), GRAFIS (Software Dr. K. Friedrich), Audaces Apparel (Audaces), COAT (COAT- EDV-Systeme) and Fashion CAD (Cad Cam Solutions), support geometrical pattern drafting from first principles using only anthropometric measurements of the target size and shape. With the help of a "digitiser" it is possible to input existing block patterns into virtually any of the various software packages that are currently available, and thus an extensive library of patterns in many sizes can be efficiently stored on the computer for future use.

A set of three-dimensional (3D) CAD software packages for virtual prototyping of clothing is now commercially available. A review of published literature has identified two distinct approaches to clothing design taken into consideration while developing 3D CAD systems. These two techniques may be categorised as the "2D to 3D" approach, which refers to draping digital 2D pattern pieces on to a 3D mannequin, and the "3D to 2D" approach which indicates the development of clothing design a 3D body and subsequently flattening the shape into $2 \mathrm{D}$ pattern pieces. A combination of these approaches is also proposed in some CAD systems. This paper reviews the historical development of 3D CAD systems for the clothing industry, and examines the available 3D CAD systems and considers their facilities and how they might be effectively exploited.

\section{Historical Developments}

Tables 1, 2 and 3 summarise the historical developments in 3D clothing systems and their major features.

One of the early 3D CAD systems for garment design was demonstrated by Hinds and McCartney in the beginning of the 1990s (Hinds and J. McCartney, 1990; Hinds et al., 1992). Their system contained a virtual mannequin for use a design platform, created by scanning a tailor's dummy, and it used a digitiser as an input device for presenting garment panels on to the virtual mannequin (Hinds et al., 1992). This early version of their CAD system could develop and visualise 3D garments, which could automatically adapt the dimensions and the surface geometry of the virtual mannequin in the work station. It did not require the designer to insert the dimensions of the garments to the system. 
Later in 2000, they proposed a CAD system with a new process of garment design covering both "3D to 2D" and "2D to 3D" approaches (McCartney et al., 2000). This system comprised three key elements: a design interface for facilitating the creation of $3 \mathrm{D}$ garment specifications by the designer, a module for pattern flattening and a drape engine based on the computational algorithm for accurate simulation of materials on a 3D body. They also demonstrated the drape simulation of two woven fabrics for $3 \mathrm{D}$ visualisation of garment panels on the $3 \mathrm{D}$ body. This marked a remarkable advancement in $3 \mathrm{D}$ CAD for garment design.

Okabe et al. (1992) gave an outline of a clothing CAD system comprising both "2D to 3D" and " $3 \mathrm{D}$ to $2 \mathrm{D}$ " approaches. First they used the programming language "FORTRAN" together with application programming interfaces in "CORE" for 3D viewing and "PLOT10" for $2 \mathrm{D}$ presentation, as part of their CAD system. Later they re-wrote the whole programme in "C++" with application programming interfaces "PHIGS" and "IDES" for both 3D and 2D screen rendering, to improve the efficiency. They successfully demonstrated the wrapping of 2D pattern shapes on to $3 \mathrm{D}$ body models and drape simulation based on the mechanical parameters of fabrics measured by the Kawabata System.

Other notable early systems targeting the "2D to 3D" clothing design approach were developed and presented by Ito et al. (1992), Fozzard and Rawling (1991, 1992), Matsuura (1993) and Rasdomakin (1995). The CAD system of Ito et al. (1992) could simulate virtual garments from differently-designed 2D pattern sets on a 3D body form to visualise the differential silhouettes, which they envisaged as a helpful tool for designers to review and modify the designs. The design system produced by Fozzard and Rawling (1991, 1992) allowed the inspection of $2 \mathrm{D}$ pattern pieces which could then be simulated as 3D clothing. Matsuura (1993) and Rasdomakin (1995) offered 3D CAD systems with pre-developed 3D blocks allowing the alteration of style-line and other design parameters by user's interactions. The CAD system of Matsuura was commercialised in Japan as the Asahi 3D system (Hardaker and Fozzard, 1998).

Kang and Kim (2000a, 2000b) developed a clothing CAD system which had a module for drafting flat patterns, a resizable virtual mannequin and a drape engine for wrapping 2D patterns on a 3D body and which also facilitated the simulation of textile materials. They 
(Kang and Kim, 2000c) also demonstrated the generation of 3D clothing designs on virtual body models with their software which subsequently allowed 2D pattern flattening. They capitalised on a stereoscopic technique using a CCD (charge-coupled device) camera to input the $3 \mathrm{D}$ shape of shirt panels into the CAD system to generate the 3D garment models. Later, in 2002, they presented a technique for 3D virtual garment generation from body scan data and this supported the extraction of 2D flat pattern pieces (Kim and Kang, 2002).

A sketch-based 3D design procedure using a virtual human model and which offered the subsequent flattening of 2D patterns was presented by Wang et al. in 2002 (Wang et al., 2002). Using Visual C++ in conjunction with OpenGL library under the Windows NT/2000 operating system, they constructed virtual prototype garments with a triangulated mesh surface, which they termed 'garment feature template', on a virtual human model built from scanned data. Through 'feature nodes encoding' using mathematical equations and subsequent 'topological graph determination', they imparted the original anthropometric features of the input human model to their 'garment feature template'. They then demonstrated how to specify the 3D profile of the 'garment feature template' using 2D lines and a regeneration of the mesh surface to represent the desired 3D design and they finally unwrapped the $2 \mathrm{D}$ pattern pieces. They also presented a concept of $3 \mathrm{D}$ grading of patterns by constructing the same garment on differently-sized virtual human models. However this process did not provide enough flexibility of $2 \mathrm{D}$ drawing on the $3 \mathrm{D}$ virtual model, as the $2 \mathrm{D}$ lines are constrained to the vertices of the mesh triangles in a single plane only. For 3D grading, the same garment has to be repeatedly constructed on different-sized virtual models, which is a very time-consuming and repetitive process.

3D modelling algorithms for CAD systems to support "2D to 3D" design were presented by Chiricota (2003) and Fuhrmann et al. (2003). In addition to the wrapping of 2D garment panels on 3D body models using geometric modelling techniques, Chiricota showed the automatic modelling of secondary garment parts such as collars, waist bands and pockets. The design system of Fuhrman et al. (2003) offered fully interaction-free dressing of a virtual human in an automated way. They developed algorithms for geometric pre-positioning of 2D patterns pieces on a virtual body in order to implement the physically- based drape modelling in a Java environment using Java3D. 
A cloth and drape simulator developed at MiraLab in Geneva is an efficient tool for dynamic simulation and animation of virtual dressed humans which may be used to produce a virtual fashion show (Thalman and Volino, 2005; Volino et al. 2005; Volino and Thalman, 2005). This modeller is integrated into their virtual garment design and prototyping software "Fashionizer" which significantly advanced the techniques used for virtual fashion shows (Thalman and Volino, 2005).

Luo and Yuen (2005) presented a CAD system, based on Visual C++6.0 and OpenGL library, which followed the " $2 \mathrm{D}$ to $3 \mathrm{D}$ " design approach but allowed the designer to modify the $2 \mathrm{D}$ pattern interactively. The most notable feature of their CAD system is that any interactive change in the $2 \mathrm{D}$ pattern pieces could make an automatic change in the corresponding $3 \mathrm{D}$ design. They described the process as 'reactive 2D/3D garment pattern design'.

The CAD system presented by Fontana et al. (2005) included a 3D modeller, a 2D CAD unit and a 3D simulator. The 3D modeller could facilitate the modification of garment design from a range of available $3 \mathrm{D}$ designs. The $2 \mathrm{D}$ CAD unit could generate $2 \mathrm{D}$ pattern pieces from $3 \mathrm{D}$ designs and the $3 \mathrm{D}$ simulation unit could replicate the fabric behaviour and drape to allow the designer to review and evaluate the fit and appearance of the garments.

Sul and Kang (2006) presented a CAD system which could mimic the "haute couture" garment-making system. The system considered fabric as virtual rectangular sheet which a user could drape onto a virtual mannequin. During the draping process it allowed the designer to remove the redundant parts of virtual fabric using the scissoring tool. The system did not have any flattening module but it could provide 2D flat pattern pieces by copying the virtual scissoring process simultaneously in 2D.

An interactive $\mathrm{CAD}$ system for drawing on a 3D mannequin and developing 3D designs from the drawing and subsequent flattening into 2D pattern pieces was described by Petrak and Rogale (2006) and Petrak et al. (2006). They used the software Rhinoceros 2.0 under the Windows 2000 operating system to develop the wireframe design of a garment and to create the fabric surface by cloth modelling techniques. 
An interesting 2D sketch-based 3D CAD system and design technique was presented by Decaudin et al. (2006) and Turquin et al. (2007). The CAD system of Decaudin et al. combined both the "3D to $2 \mathrm{D}$ " and " $2 \mathrm{D}$ to $3 \mathrm{D}$ " approaches. Their CAD system allowed the designer to sketch garment contours onto a $2 \mathrm{D}$ view of a mannequin and could generate $3 \mathrm{D}$ virtual garments from the $2 \mathrm{D}$ sketch. They also demonstrated flattening of the $2 \mathrm{D}$ pattern from the finished 3D design. Turquin et al. focused on the simulation of virtual garments from 2D sketches in a similar way to Decaudin et al.

Kim and Park (2007) described a technique for generating 3D designs in space and for developing 2D flat patterns from the 3D shape. In their CAD system, they divided a garment into two zones: a fit zone and a fashion zone. For fit zone modelling, they captured the surface of a physical mannequin by a multi-joint coordinate measurement system and reconstructed the mannequin's topography in the computer. For the fashion zone they followed the CAD technique without considering the body geometry, rather considering the aesthetic appearance of the garment.

Fang et al. (2008a, 2008b) proposed a clothing design process which covers both the "3D to $2 \mathrm{D}$ " and "2D to 3D" approaches. They demonstrated the creation of 3D upper body garment designs on a virtual mannequin made from body scan data. They developed the mannequinbased 3D garment designing and restyling tools using Microsoft foundation classes (MFS) and OpenGL by exploiting the embedded mathematical formulae (Fang et al., 2005a, 2005b). They also demonstrated the 2D flattening of patterns from 3D designs, and the visualisation of virtual outerwear clothing with different textures, but without considering the material properties. In an earlier work, they used 'object-oriented methodology' and 'geometric modelling theory' to develop 3D clothing design software tools for garment designers and also demonstrated the design of 3D shirt collars using their developed software tools (Fang, 2003).

\section{Available 3D CAD Systems for the Clothing Industry}

Commercially available 3D CAD systems for 3D garment visualisation and virtual try-on software can be categorised into two groups, based on the underlying working procedure, to create $3 \mathrm{D}$ designs. One group, which includes software such as Virtualfashion $^{\circledR}$ (Reyes 
Infografica) and TPC Parametric Pattern Generator (TPC), allows designers to develop garment silhouettes and styles in a 3D environment according to their preference. Other types of $3 \mathrm{D}$ CAD system allow the importation of $2 \mathrm{D}$ pattern pieces from the appropriate $2 \mathrm{D} C A D$ software to wrap them onto a virtual model in order to visualise the virtual product and also to simulate fabric drape and fit. This group includes Vstitcher ${ }^{\mathrm{TM}}$ (Browzwear), Accumark Vstistcher $^{\mathrm{TM}}$ (Gerber), Haute Couture 3D (PAD system), Modaris 3D FIT (Lectra), efit Simulator (Tukatech), 3D Runway (OptiTex), Vidya (Assyst-Bullmer).

For $3 \mathrm{D}$ to $2 \mathrm{D}$ pattern unwrapping, there has been no 3D CAD system readily available until recently which could be directly used in the clothing industry. Among the available software packages $3 D$ Interactive software (TPC) and the flattening tool of $3 D$ Runway (OptiTex) provide the capability to execute pattern unwrapping in a very limited context. The DesignConcept software (Lectra) is capable of executing 3D to 2D pattern unwrapping, but is currently being promoted for use in car seat design and for technical textiles applications.

Major features of the available CAD systems are summarised in Table 4.

\section{Virtualfashion $^{\circledR}$ (Reyes Infografica)}

Virtualfashion $^{\circledR}$, which is available in two different versions: VF Professional and VF basic, provides a $3 \mathrm{D}$ workspace for the designer to create $3 \mathrm{D}$ designs interactively on $3 \mathrm{D}$ garment moulds linked with virtual human models. The software contains male and female virtual models for design purposes and allows the designer to import models from other software such as Poser and Daz. It also allows the designer to change the features of the models such as posture, facial gesture and skin colour. The designer can select any garment mould associated with either a male or female model and can start the garment design by modifying the mould and can finally apply fabric to the design from a fabric library. The software offers a selection of fabrics ranging from heavy cotton to silk, wool and denim but does not allow the designer to create new fabrics by inputting any mechanical properties, rather it only allows the changing of colour and texture. The software has a drape module which can simulate fabric behaviour through physics-based calculation. The system offers the opportunity to create a virtual fashion show in association with the software "VF show" from the same supplier. The software is useful for fashion designing, product line creation, 
decision making and visual communication but it does not have any link with the pattern creation process (VF Professional 1.5 User Reference)

\section{Modaris 3D Fit (Lectra)}

Modaris 3D Fit from Lectra is a 3D virtual prototyping solution which associates 2D patterns, fabric information and 3D virtual models. It enables simulation of 3D design from 2D pattern pieces developed by a wide range of $2 \mathrm{D}$ CAD software and helps the designer to validate fabrics, motifs and colours. It allows an on-site or remote review of the virtual prototypes in three dimensions and provides the opportunity to check garment fit in various fabrics and sizes. It has a broad library of over 120 materials together with their mechanical characteristics. It also allows the designer to input new fabric properties in order to view differential drape.

\section{Vstitcher $^{\mathrm{TM}}$ (Browzwear) and Accumark Vstitcher ${ }^{\mathrm{TM}}$ (Gerber)}

$V_{\text {Stitcher }}{ }^{\mathrm{TM}}$ from Browzwear is 3D design and visualisation software capable of turning 2D patterns into 3D virtual garments on customisable virtual models. It is interfaced with pattern design, grading and marker-making software (AccuMark from Gerber) and is offered to the market as AccuMark VStitcher ${ }^{\mathrm{TM}}$ by Gerber. The software allows customisation of the integrated virtual human models by means of a range of parameters, from age and gender, through body measurements and posture, to skin tone and hair style, and even through the stages of pregnancy. It can convert the $2 \mathrm{D}$ pattern pieces into $3 \mathrm{D}$ garment designs which represent the realistic draping behaviour of fabric, based on physical characteristics. Its drape simulation is based on mathematical and physical algorithms. The software allows the designer to introduce any required changes to the $2 \mathrm{D}$ pattern pieces which reflect into the $3 \mathrm{D}$ design automatically. It also offers texture mapping which means the adding of photographically derived representation of fabric, stitches, prints and any other attachments on the 3D design. It helps to evaluate the fit of simulated garments on accurately-sized virtual models and allows the virtual design to be communicated with any remote customer or 
partner via the Internet platform. Vsticher ${ }^{\mathrm{TM}}$ also makes available the facility to realise realtime fit approval sessions online, across the globe when connected with appropriate hardware and additional software.

\section{Haute Couture 3D (PAD system)}

Principally similar to VStitcher ${ }^{\mathrm{TM}}$, Haute Couture $3 D(H C 3 D)$ is visualisation software which can produce virtual 3D garments from 2D pattern pieces. It contains a cloth simulation tool named Syflex ${ }^{\mathrm{TM}}$. In addition to cloth simulation, it allows the application of colour, textures and prints through its texture mapping tools. Together with the facilities for modifying the 3D design, it also offers customisation of the fabric properties in order to view the variation in drape output. This software is compatible with 3D graphic software Maya ${ }^{\mathrm{TM}}$ and other 3D animation applications and can also be used to meet the needs of the animation and film industries.

\section{eFit Simulator ${ }^{\mathrm{TM}}$ (Tukatech)}

The eFit Simulator ${ }^{\mathrm{TM}}$ is a software solution which produces 3D virtual prototypes of garments from 2D patterns and fabric properties on the virtual models. It allows digital prototype samples to be sent around the world through e-mail and also provides designers with a 'virtual fit session' online, in real time. Using this software, it is possible for users to see a garment from any angle in a static or dynamic pose and to create dynamic storyboards for presentation purposes.

\section{Vidya (Assyst-Bullmer)}

Vidya is 3D draping software which has found applications in the clothing industry for product-development and in video games, animated films and Internet shops. It enables the creation of customised virtual mannequins based on the customer's market and specific size tables and body-scanned data. It can visualise 3D garment design from $2 \mathrm{D}$ patterns and simulate fabric drape on a virtual mannequin which can be animated to review the fit. It can 
simulate seams, buttons, appliqués, seam lines, linings and folds on the $3 \mathrm{D}$ design. It allows the designer to add colours and textures as per the preference. It comes with a range of fabrics in its standard library which can be expanded by inputting any fabric characteristics taken from objective fabric measurement system such as KES and FAST.

\section{D Runway (OptiTex)}

3D Runway is cloth simulation software system for 3D garment draping and visualisation and it is based on 2D CAD patterns and real fabric characteristics. It offers the user a range of parametric mannequins featuring sixty five adjustable body measurements and several posture positions. The designer can visualise any design details on virtual garments using the texture mapping tools and can check the fit on virtual fit model in static or dynamic positions. The software also contains a flattening tool which can transform the 3D object's surface into 2D pattern pieces to a limited extent.

\section{TPC Parametric Pattern Generator and 3D Interactive Software}

Parametric Pattern Generator (PPG) from TPC (HK) Limited is software which has been developed to allow the design of garments directly on a virtual mannequin in a $3 \mathrm{D}$ environment. It comes with a set of virtual mannequins as design platforms and it can also create a virtual mannequin using body-scanned data. It can visualise garment design directly on the selected virtual mannequin. It allows the designer to evaluate the silhouette and volume of the garment as well as to adjusting and modifying the design. Its 2D module can generate 2D patterns simultaneously, based on the designer's adjustment and modifications to the 3D design. It facilitates automatic pattern grading. 3D Interactive software from the same supplier is claimed to be able to convert 3D virtual design into $2 \mathrm{D}$ pattern pieces automatically.

\section{DesignConcept (Lectra)}

Design Concept from Lectra is a '2D and 3D' software solution based on TOPSOLID, a software package from another French company MISSLER used for 3D mechanical design. The software is currently being offered for the automobile and technical textiles industries with the name DesignConcept Auto and DesignConcept TechTex. The distinct feature of this 
software is that it is capable of producing $2 \mathrm{D}$ templates from $3 \mathrm{D}$ designs using the flattening mechanism. This offers the opportunity to execute "3D to $2 \mathrm{D}$ pattern unwrapping" for clothing product-development purposes. It was used experimentally for the development of parametric virtual models to create $3 \mathrm{D}$ designs and for extraction of $2 \mathrm{D}$ pattern pieces (Sayem, 2004). However this process involved the importing of a virtual model in to the software, and necessitates the development of size databases which are not available with the software currently.

\section{Applications and Advantages}

Okabe et al. (1992) proposed to position the 3D CAD system at the centre of a textile information network to process textile design and clothing design synchronously and in parallel. Once a designer finalises a design, all of the relevant information in respect of material properties and garment properties can be easily communicated to the material processing units and stitching units if the 3D clothing CAD system is linked with the textile supply networks. This provides not only a time saving solution for communication throughout the textiles supply chain, but also helps to meet any communication gap between the designers, retailers and manufacturers.

In order to take advantage of labour market differentials, clothing retailers in Europe and America have adopted offshore sourcing and production strategies (Christerson and Appelbaum, 1995; Firoz and Ammaturo, 2002; Gereffi and Memedovic, 2003). As a result, the majority of the World's clothing production is concentrated in the lower labour cost countries; usually far away from European and American clothing retailers. The geographical separation between source and destination means that physical prototyping; transporting the retailers' designs that have been made up in a designated manufacturing plant, absorbs a proportion of a garment's development. When this process needs to be repeated to rectify problems arising during assembly or fit, the distance involved inevitably increases the development lead time even further. In preparation for decision-making on product selection and prior to the commencement of production, usually between two and ten physical prototypes are required to be made within the existing product-development systems followed traditionally (Lectra Bylined Article); it involves a high cost and is responsible for much of the lead-time attached to a garment development. 
To cope with rapid fashion changes and also to reduce the costs, there is pressure from the retail sector to shorten product-development as much as possible and also to minimise the investment in physical prototyping. Virtual prototyping is offered as a solution to this problem. Draping the 2D patterns onto a virtual human model to visualise the 3D appearance of the clothing, coupled with realistic simulation of the material behaviour provides the opportunity to check fit and pattern flaws so that the initial $2 \mathrm{D}$ pattern pieces might be refined. It is claimed by the software suppliers that such an approach will reduce the dependency on physical prototyping, and will shorten the product-development lead time and the associated costs when communicated over the Internet platform (Ernst, 2009; Lectra Customer Success Story; Tukatech).

\section{Conclusion}

According to the 3D CAD system suppliers Lectra, Gerber, Tukatech and others; virtual prototyping and virtual try-on processes can drastically reduce product-development time and cost. Virtual review and evaluation of fit with realistically simulated fabric behaviour can enable faster detection of errors and earlier correction of design elements, material selection and assembly. At the same time, virtual prototypes can be used as a marketing aid for online product presentation and Internet-based retailing.

The use of CAD systems for 3D garment visualisation from 2D patterns has recently been started in the clothing industry. No industrial application of any 3D to $2 \mathrm{D}$ pattern unwrapping technique is yet to be made, due to the non-availability of an appropriate CAD system on the market. The use of $3 \mathrm{D}$ to $2 \mathrm{D}$ pattern unwrapping techniques will usefully abbreviate the development process in more than one respect. It will not only combine the fashion design and pattern drawing into single steps, but it will also cut the garment development time and manpower involvement significantly in a way that will provide a significant commercial advantage. Moreover, adopting such an approach may serve to redefine the concept of fashion design and pattern creation. To realise this concept in practice, the CAD system must be able to flatten the 3D surface of a garment into 2D and should have a sketch-based interface to accommodate the requirements of the designers. 


\section{References}

Adobe Inc., http://www.adobe.com/products/illustrator/ (Accessed 27 August 2009)

Assyst-Bullmer, http://www.assystbullmer.co.uk/pdfs/vidya_E_merged_screen.pdf (Accessed 27 August 2009)

Audaces, http://www.audaces.com/index.php?pgn=14\&lang=2 (Accessed 27 August 2009)

Browzwear, http://www.browzwear.com/vstitcher.htm (Accessed 27 August 2009)

Cad Cam Solutions, http://www.fashioncad.net/fashioncadcontact.htm, (Accessed 27 August 2009)

Chiricota, Y., 2001. Geometrical modelling of garments, International Journal of Clothing Science and Technology, 13(1), 38-52.

Christerson, B. and Appelbaum, R., 1995. Global and local subcontracting: space, ethnicity, and the organization of Apparel Production, World Development, 23 (8), 13631374 .

COAT-EDV-Systeme, http://www.coat.de/en/product/intro.html, (Accessed 27 August 2009)

Corel Corp., http://www.corel.com/servlet/Satellite/gb/en/Product/ (Accessed 27 August 2009)

Decaudin, P.; Julius, D.; Wither, J.; Boissieux, L.; Sheffer, A. and Cani, M., 2006. Virtual garments: A fully geometric approach for clothing design, EUROGRAPHICS 2006, $25(3), 625-634$.

Ernst, M., 2009. CAD/CAM Powerful, Textile Network, 4, 20-21. 
Fang, J. and Ding, Y., 2008a. Expert-based customized pattern-making automation: Part I. Basic patterns, International Journal of Clothing Science and Technology, 20 (1), 26-40.

Fang, J. and Ding, Y., 2008b., Expert-based customized pattern-making automation: Part II. Dart design, International Journal of Clothing Science and Technology, 20 (1), 41-56.

Fang, J. and Liao, C., 2005a. 3D apparel creation based on computer mannequin model Part I: system kernel and formulas, International Journal of Clothing Science and Technology, 17 (5), 292-306.

Fang, J. and Liao, C., 2005b. 3D apparel creation based on computer mannequin model Part II: implementations, International Journal of Clothing Science and Technology, 17 (5), 307319.

Fang, J., 2003. 3D collar design creation, International Journal of Clothing Science and Technology, 15 (2), 88-106.

Firoz, N.M. and Ammaturo, C.R., 2002. Sweatshop labour practices: The bottom line to bring change to the new millennium case of the apparel industry, Humanomics, 18 (1/2), 2945.

Fontana, M.; C. Rizzib, C. and Cuginic, U., 2005. 3D virtual apparel design for industrial applications, Computer-Aided Design, 37, 609-622.

Fozzard, G.J.W. and Rawling, A.J., 1991. Simulation of dressing and drape for garment CAD, Proceedings from the 6th International Forum on CAD, 157-62. (cited in Hardaker and Fozzard, 1998).

Fozzard, G.J.W. and Rawling, A.J., 1992. CAD for garment design - Effective use of the third dimension, Proceedings of the Eighth National Conference on Manufacturing Research, 183-189. (cited in Hardaker and Fozzard, 1998). 
Fuhrmann, A.; Gross, C.; Luckas, V. and Weber, A., 2003. Interaction-free dressing of virtual humans, Computers \& Graphics, 27, 71-82.

Gerber, http://www.gerbertechnology.com/downloads/pdf/AccuMark_V-Stitcher_Apparel_E.pdf (Accessed 27 August 2009)

Gereffi, G. and Memedovic, O., 2003. The global apparel value chain: What prospects for upgrading by developing countries? [online]. United Nations Industrial Development Organization (UNIDO), Vienna. Available from:

http://www.unido.org/fileadmin/media/documents/pdf/Services_Modules/Apparel_Value_Ch ain.pdf (Accessed 27 August 2009)

Hardaker, C.H.M. and Fozzard, G.J.W., 1998. Towards the virtual garment: threedimensional computer environments for garment design, International Journal of Clothing Science and Technology, 10 (2), 114-127.

Hinds, B.K. and McCartney, J., 1990. Interactive garment design, The Visual Computer, 6, 53-61.

Hinds, B.K.; McCartney, J.; Hadden, C. and Diamond, J., 1992. 3D CAD for Garment Design, International Journal of Clothing Science and Technology, 4 (4), 6-14.

Ito, I.; Kawauchi, K.; Odagaki, C. and TMSJ. M., 1992. Three-dimensional computer system for automatic pattern making and simulation, Journal of the Textile Machinery Society of Japan, 38 (3), 68-77.

Kang, T.J. and Kim, S. M., 2000a. Development of three dimensional apparel CAD system Part 1: flat garment pattern drafting system, International Journal of Clothing Science and Technology, 12 (1), 26-38.

Kang, T.J. and Kim, S. M., 2000b. Development of three dimensional apparel CAD system, Part II: prediction of garment drape shape, International Journal of Clothing Science and Technology, 12 (1), 39-49. 
Kang, T.J. and Kim, S. M., 2000c. Optimized garment pattern generation based on threedimensional anthropometric measurement, International Journal of Clothing Science and Technology, 12 (4), 240-254.

Kim, S.M. and Kang, T. J., 2002. Garment pattern generation from body scan, ComputerAided Design, 35, 611-618.

Kim, S. and Park, C. K., 2007. Basic garment pattern generation using geometric modelling method, International Journal of Clothing Science and Technology, 19 (1), 7-17.

Koppermann, http://www.koppermann.com/e/texdesign/kc_e_design.html, (Accessed 27 August 2009)

Lectra, http://www.lectra.com (Accessed 27 August 2009)

Lectra Bylined Article, The advantages of virtual 3D prototyping in the apparel industry [online], available from:

http://www.lectra.com/binaries/Apparel_3D_Bylined_en_V1a_tcm31-119223.pdf (Accessed 27 August 2009)

Lectra Customer Success Story [online], available from:

http://www.lectra.com/binaries/Modaris_3DFit_KappAhl_success-story_en_tcm31-96786.pdf (Accessed 27 August 2009)

Luo, G. Z and Yuen, M.M.F., 2005. Reactive 2D/3D garment pattern design modification, Computer-Aided Design, 37, 623-630.

Matsuura, S., 1993. Shape visualisation method and apparatus, German Patent No. 4301 698/1993 (cited in Hardaker and Fozzard, 1998).

McCartney, J.; Hinds, B.K.; Seow, B.L. and Gong, D., 2000. Dedicated 3D CAD for garment modelling, Journal of Materials Processing Technology, 107, 31-36. 
McCartney, J.; Hinds, B.K. and Seow, B.L., 1999. The flattening of triangulated surfaces incorporating darts and gussets, Computer-Aided Design, 31, 249-260.

Okabe, H.; Imaoka, H., Tomih, T. and Niwaya, H., 1992. Three dimensional apparel CAD system, Computer Graphics, 26 (2), 105-110.

Optitex, http://www.optitex.com/en/products/3DRunway_Tools (Accessed 27 August 2009)

PAD System, http://www.padsystem.co.nz/3D_simulation.php (Accessed 27 August 2009)

Petrak, S. and Rogale, D., 2006. Systematic representation and application of a 3D computer-aided garment construction method, Part I: 3D garment basic cut construction on a virtual body model, International Journal of Clothing Science and Technology, 18 (3), 179187.

Petrak, S.; Rogale, D. and Mandekic'-Botteri, V., 2006. Systematic representation and application of a 3D computer-aided garment construction method Part II: spatial transformation of 3D garment cut segments, International Journal of Clothing Science and Technology, 18 (3), 188-199.

Rasdomakhin, N., 1995. Three dimensional clothing design, Internal report, St Petersburg University of Technology and Design. (cited in Hardaker and Fozzard, 1998).

Reyes Infografica, http://www.virtual-fashion.com (Accessed 27 August 2009)

Sayem, A.S.M., 2004. Beitrag zur Entwicklung parametrischer virtueller Formkörper weiblicher Personen zur dreidimensionalen Konstruktion von körpernaher Bekleidung und Miederwaren, Masterarbeit Nr. 1275. Thesis (MSc.), Technische Universitaet Dresden (TU Dresden), Germany.

Software Dr. Friedrich, http://www.coat.de/index_e.html (Accessed 27 August 2009) 
Sul, I.H. and Kang, T.J., 2006. Interactive garment pattern design using virtual scissoring method, International Journal of Clothing Science and Technology, 18 (1), 31-42.

Thalmann, N. M. and Volino, P., 2005. From early draping to haute couture models: 20 years of research, Visual Computer, 21, 506-519.

TPC, http://www.tpc-intl.com/software.asp (Accessed 27 August 2009)

Tukatech, http://www.tukatech.com/products/efit/ (Accessed 27 August 2009)

Turquin, E.; Wither, J.; Boissieux, L.; Cani, M. and Hughes, J. F., 2007. A sketch-based Interface for Clothing Virtual Characters, IEE Computer Graphics and Applications, 72-81.

VF Professional 1.5 User Reference, Reyes Infografica S.L., Spain, http://www.virtualfashion.com/html/en/downloads_vfpro.php (Accessed 27 August 2009)

Volino, P.; Cordier, F. and Thalman, N.M., 2004. From early virtual garments simulation to interactive fashion design, Computer-Aided Design, 37, 593-608.

Wang, C.C.L.; Wang, Y. and Yuen, M.M.F., 2002. Feature based 3D garment design through 2D sketches, Computer-Aided Design, 35, 659-672. 
Table 1. Developments in 3D Clothing CAD Systems (1990 to 2000)

\begin{tabular}{|c|c|c|c|c|c|c|c|c|c|}
\hline $\begin{array}{l}\text { Developers } \\
\text { Features }\end{array}$ & $\begin{array}{c}\text { Hinds } \\
\text { and } \\
\text { McCartn } \\
\text { ey, } 1990\end{array}$ & $\begin{array}{c}\text { Hinds et } \\
\text { al., } \\
1992\end{array}$ & $\begin{array}{c}\text { Okabe } \\
\text { et al.,, } \\
1992\end{array}$ & $\begin{array}{c}\text { Ito et } \\
\text { al., } \\
1992\end{array}$ & $\begin{array}{c}\text { Fozzard } \\
\text { and } \\
\text { Rawling, } \\
1991- \\
1992\end{array}$ & $\begin{array}{c}\text { Matsu } \\
\text { ura, } \\
1993\end{array}$ & $\begin{array}{l}\text { Rasdoma } \\
\text { kin, } 1995\end{array}$ & $\begin{array}{c}\text { Kang } \\
\text { and } \\
\text { Kim, } \\
2000\end{array}$ & $\begin{array}{c}\text { MacCa } \\
\text { rtney } \\
\text { et al., } \\
2000\end{array}$ \\
\hline $\begin{array}{l}\text { Non-resizable virtual } \\
\text { mannequin }\end{array}$ & $\sqrt{ }$ & $\sqrt{ }$ & $\sqrt{ }$ & $\sqrt{ }$ & $\sqrt{ }$ & $\sqrt{ }$ & $\sqrt{ }$ & & $\sqrt{ }$ \\
\hline Resizable virtual mannequin & & & & & & & & $\sqrt{ }$ & \\
\hline "2D to 3D" design approach & & & & $\sqrt{ }$ & $\sqrt{ }$ & & & & \\
\hline “3D to 2D" design approach & & $\sqrt{ }$ & & & & & & & \\
\hline Combined design approach & & & $\sqrt{ }$ & & & & & & $\sqrt{ }$ \\
\hline Realistic cloth simulation & & & $\sqrt{ }$ & $\sqrt{ }$ & $\sqrt{ }$ & & & $\sqrt{ }$ & $\sqrt{ }$ \\
\hline $\begin{array}{l}\text { 3D blocks allowing } \\
\text { modification }\end{array}$ & & & & & & $\sqrt{ }$ & $\sqrt{ }$ & & \\
\hline 3D grading & & & & & & & & & \\
\hline Sketched-based technique & $\sqrt{ }$ & $\sqrt{ }$ & & & & & & & \\
\hline
\end{tabular}


Table 2. Developments in 3D Clothing CAD Systems (2001 to 2005)

\begin{tabular}{|c|c|c|c|c|c|c|c|c|}
\hline $\begin{array}{l}\text { Developers } \\
\text { Features }\end{array}$ & $\begin{array}{c}\text { Kim } \\
\text { and } \\
\text { Kang, } \\
2002\end{array}$ & $\begin{array}{l}\text { Wang } \\
\text { et al., } \\
2002\end{array}$ & $\begin{array}{l}\text { Chiricot } \\
\text { a, } 2003\end{array}$ & $\begin{array}{c}\text { Fuhrma } \\
\text { nn et } \\
\text { al., } \\
2003\end{array}$ & $\begin{array}{l}\text { Thalman } \\
\text { and Volino, } \\
2005\end{array}$ & $\begin{array}{l}\text { Luo and } \\
\text { Yuen, } \\
2005\end{array}$ & $\begin{array}{l}\text { Fontana } \\
\text { et al., } \\
2005\end{array}$ & $\begin{array}{l}\text { Fang } \\
\text { et al., } \\
2005\end{array}$ \\
\hline $\begin{array}{l}\text { Non-resizable virtual } \\
\text { mannequin }\end{array}$ & $\sqrt{ }$ & $\sqrt{ }$ & & $\sqrt{ }$ & $\sqrt{ }$ & $\sqrt{ }$ & & $\sqrt{ }$ \\
\hline \multicolumn{9}{|l|}{ Resizable virtual mannequin } \\
\hline “2D to 3D" design approach & & & $\sqrt{ }$ & $\sqrt{ }$ & $\sqrt{ }$ & $\sqrt{ }$ & & \\
\hline “3D to 2D" design approach & $\sqrt{ }$ & $\sqrt{ }$ & & & & & & \\
\hline \multicolumn{9}{|l|}{ Combined design approach } \\
\hline Realistic cloth simulation & & & & $\sqrt{ }$ & $\sqrt{ }$ & $\sqrt{ }$ & $\sqrt{ }$ & \\
\hline $\begin{array}{l}\text { 3D blocks allowing } \\
\text { modification }\end{array}$ & & & & & & & $\sqrt{ }$ & $\sqrt{ }$ \\
\hline $3 \mathrm{D}$ grading & & $\sqrt{ }$ & & & & & & \\
\hline Sketched-based technique & & & & & & & & \\
\hline
\end{tabular}


Table 3. Developments in 3D Clothing CAD Systems (2006 onwards)

\begin{tabular}{|c|c|c|c|c|c|c|}
\hline $\begin{array}{l}\text { Developers } \\
\text { Features }\end{array}$ & $\begin{array}{l}\text { Sul and } \\
\text { Kang, } \\
2006\end{array}$ & $\begin{array}{c}\text { Petrak and } \\
\text { Rogale, } 2006, \\
\text { Petrak et al., } \\
2006\end{array}$ & $\begin{array}{l}\text { Decaudin } \\
\text { et al. } \\
2006\end{array}$ & $\begin{array}{c}\text { Turqui } \\
\text { n et } \\
\text { al., } \\
2007 \\
\end{array}$ & $\begin{array}{c}\text { Kim and } \\
\text { Park, } 2007\end{array}$ & $\begin{array}{l}\text { Fang et al., } \\
2008\end{array}$ \\
\hline $\begin{array}{l}\text { Non-resizable virtual } \\
\text { mannequin }\end{array}$ & $\sqrt{ }$ & $\sqrt{ }$ & $\sqrt{ }$ & & & $\sqrt{ }$ \\
\hline \multicolumn{7}{|l|}{ Resizable virtual mannequin } \\
\hline "2D to 3D" design approach & $\sqrt{ }$ & & & $\sqrt{ }$ & & \\
\hline “3D to 2D" design approach & & $\sqrt{ }$ & & & $\sqrt{ }$ & \\
\hline Combined design approach & & & $\sqrt{ }$ & & & $\sqrt{ }$ \\
\hline Realistic cloth simulation & & $\sqrt{ }$ & $\sqrt{ }$ & & & \\
\hline \multicolumn{7}{|l|}{$\begin{array}{l}\text { 3D blocks allowing } \\
\text { modification }\end{array}$} \\
\hline \multicolumn{7}{|l|}{ 3D grading } \\
\hline Sketched-based technique & & & $\sqrt{ }$ & $\sqrt{ }$ & & \\
\hline
\end{tabular}


Table 4. Available 3D CAD Systems for the Clothing Industry

\begin{tabular}{|c|c|c|c|c|c|c|c|c|c|c|}
\hline Software & $\begin{array}{l}\text { Virtual- } \\
\text { fashion }\end{array}$ & $\begin{array}{c}\text { Moda } \\
\text { ris } \\
\text { 3D } \\
\text { Fit }\end{array}$ & $\begin{array}{l}\text { Vstitch } \\
\text { er }^{\mathrm{Tm}}\end{array}$ & $\begin{array}{l}\text { Haute } \\
\text { Coutu } \\
\text { re 3D }\end{array}$ & $\begin{array}{c}\text { eFit } \\
\text { Simula } \\
\text { tor }^{\mathrm{TM}}\end{array}$ & Vidya & $\begin{array}{c}\text { 3D } \\
\text { Runwa } \\
\text { y }\end{array}$ & $\begin{array}{l}\text { TPC } \\
\text { PPC }\end{array}$ & $\begin{array}{c}\text { TPC 3D } \\
\text { Interac } \\
\text { tive }\end{array}$ & $\begin{array}{c}\text { Design } \\
\text { Concep } \\
t\end{array}$ \\
\hline $\begin{array}{l}\text { Wrapping 2D patterns on } \\
\text { 3D body }\end{array}$ & & $\sqrt{ }$ & $\sqrt{ }$ & $\sqrt{ }$ & $\sqrt{ }$ & $\sqrt{ }$ & $\sqrt{ }$ & & & \\
\hline $\begin{array}{l}\text { Developing 3D design on } \\
\text { 3D body }\end{array}$ & $\sqrt{ }$ & & & & & & & $\sqrt{ }$ & $\sqrt{ }$ & $\sqrt{ }$ \\
\hline $\begin{array}{l}\text { Flattening 2D patterns from } \\
\text { 3D design }\end{array}$ & & & & & & & $\sqrt{ }$ & & $\sqrt{ }$ & $\sqrt{ }$ \\
\hline Realistic fabric draping & $\sqrt{ }$ & $\sqrt{ }$ & $\sqrt{ }$ & $\sqrt{ }$ & $\sqrt{ }$ & $\sqrt{ }$ & & & & \\
\hline Adjustable mannequin & & $\sqrt{ }$ & $\sqrt{ }$ & & $\sqrt{ }$ & $\sqrt{ }$ & $\sqrt{ }$ & & & \\
\hline $\begin{array}{l}\text { Dynamic pose/ virtual } \\
\text { fashion show }\end{array}$ & $* \sqrt{ }$ & & & $\sqrt{ }$ & $\sqrt{ }$ & $\sqrt{ }$ & $\sqrt{ }$ & & & \\
\hline Online fit session & & & $\sqrt{ }$ & & $\sqrt{ }$ & & $\sqrt{ }$ & & & \\
\hline
\end{tabular}

Note: * when used together with the software "VFshow" 
